\title{
FATORES DE ROTATIVIDADE EM UMA EMPRESA DO SEGMENTO
}

\author{
METALOMECÂNICO
}

\author{
Gabriela Aver ${ }^{1}$ \\ https://orcid.org/0000-0002-7565-7387 \\ Daniel Hank Miri ${ }^{2}$ \\ https://orcid.org/0000-0002-0765-6868 \\ Cassiane Chais $^{3}$ \\ https://orcid.org/0000-0002-1922-9273 \\ Juliana Matte M $^{4}$ \\ https://orcid.org/0000-0003-0945-2479 \\ Paula Patricia Ganzer ${ }^{5}$ \\ https://orcid.org/0000-0003-4006-6517 \\ Pelayo Munhoz Olea ${ }^{6}$ \\ https://orcid.org/0000-0003-2183-8112
}

Recebido em: 20 nov. 2019

Aceito em: 25 set. 2020

Como citar este artigo: AVER, G.; MIRI, D. H.; CHAIS, C.; MATTE, J.; GANZER, P. P.; OLEA, P. M. FATORES DE ROTATIVIDADE EM UMA EMPRESA DO SEGMENTO METALOMECÂNICO:

ROTATIVITY FACTORS IN A MECHANICAL METAL SEGMENT COMPANY. Revista Visão: Gestão

Organizacional, Caçador (SC), Brasil, v. 9, n. 2, p. 168-186, 2020. DOI:

10.33362/visao.v9i2.2155. Disponível em:

https://periodicos.uniarp.edu.br/index.php/visao/article/view/2155.

Resumo: Com a crise econômica dos últimos anos no país, notaram-se constantes mudanças no mundo do trabalho como o aumento de candidatos em busca de recolocação profissional e a queda de vagas ofertadas pelas empresas. Nesse cenário, o setor de Recursos Humanos exerce um papel fundamental dentro das empresas, pois precisa utilizar técnicas para selecionar candidatos que atendam ao perfil do cargo e a demanda da empresa em que, se inicia o processo de contratação de novos funcionários. Diante disso, este estudo tem como tema de pesquisa a rotatividade em uma empresa do segmento metalomecânico de Caxias do Sul-Rio Grande do Sul com vistas a analisar os principais fatores determinantes da rotatividade. Assim, a pesquisa, realizada por meio de uma survey aplicada a 90 funcionários de uma empresa de grande porte do segmento metalomecânico, demonstrou que os mesmos consideram o ambiente de trabalho o fator determinante para a ocorrência da rotatividade na

\footnotetext{
${ }^{1}$ Universidade de Caxias do Sul. Email: gabriela.aver@yahoo.com.br.

${ }^{2}$ Universidade de Caxias do Sul. Email: dhmiri@ucs.br.

${ }^{3}$ Universidade de Passo Fundo. Email: cassichais@gmail.com.

${ }^{4}$ Universidade de Caxias do Sul. Email: ju.cxs1@gmail.com.

${ }^{5}$ Faculdade CNEC Farroupilha. Email: ganzer.paula@gmail.com.

${ }^{6}$ Universidade Federal do Rio Grande. Email: pelayo.olea@gmail.com.
} 
empresa. Evidenciou-se, ainda, que, a fim de mudar o quadro de insatisfação, a empresa precisa buscar alternativas para a união das equipes de trabalho, conscientizar as pessoas do quão importante é manter relacionamentos saudáveis com os colegas e, criar um senso comum de cooperação, coleguismo e respeito ao próximo.

Palavras-chave: Liderança. Motivação. Rotatividade.

\section{ROTATIVITY FACTORS IN A MECHANICAL METAL SEGMENT COMPANY}

Abstract: With the economic crisis of the last few years in the country, constant changes in the world of work have been noticed, such as the increase of candidates in search of professional relocation and the decrease of vacancies offered by companies. In this scenario, the Human Resources sector plays a fundamental role within organizations, as it needs to use techniques to select candidates that meet the profile of the position and the demand of the company in which the process of hiring new employees begins. Therefore, this study has as its research theme the turnover in a company in the metalmechanic segment of Caxias do Sul-Rio Grande do Sul in order to analyze the main determinants of turnover. Thus, the survey, carried out through a survey applied to 90 employees of a large company in the metal-mechanic segment, showed that they consider the work environment the determining factor for the occurrence of turnover in the company. It was also evident that, in order to change the situation of dissatisfaction, the organization needs to seek alternatives for the union of work teams, make people aware of how important it is to maintain healthy relationships with colleagues and create a common sense of cooperation, collegiality and respect for others.

Keywords: Leadership. Motivation. Rotativity.

\section{INTRODUÇÃO}

O mercado de trabalho está passando por transformações. A oferta de vagas diminuiu, pois há mais demanda por parte de candidatos que estão à procura de emprego, e as empresas estão reduzindo custos, o que, consequentemente, reflete na diminuição do quadro de funcionários. Tais aspectos impactam, assim, o processo de recrutamento e seleção como um todo, definindo as pessoas que irão integrar o quadro da empresa de acordo com os seus perfis (BARBIERI, 2016).

O município de Caxias do Sul é conhecido como um dos principais polos industriais do Brasil. Em um estudo sobre o desenvolvimento socioeconômico da cidade, levando em conta fatores como o Valor Adicionado Bruto (VAB) dos setores de agropecuária, indústria e serviços no período de 1985 até 2007, chamou atenção o aumento da participação do setor de serviços no VAB total, ultrapassando o setor da indústria, que é o principal foco do município (OBSERVATÓRIO DO TRABALHO, 2011).

Segundo Corrêa e Caon (2012, p. 23), "a importância das atividades econômicas de serviços apresenta um histórico atrativo". Em todos os países desenvolvidos, o setor de serviços ocupa um lugar de destaque na economia. O principal indicador para confirmar essa tese tem 
sido a participação do setor na ocupação de mão de obra e na geração de riqueza, o que repercute no Produto Interno Bruto (PIB). O setor de serviços, além der ser o agente responsável pela maior parcela do PIB mundial, apresenta-se como a parte mais ativa da economia, por sua participação no PIB e quanto pelo crescimento do número de empregos no setor (CORRÊA; CAON, 2012).

Nesse contexto, a gestão de recursos humanos, ao compreender as práticas de emprego favoráveis aos empregados, as práticas de trabalho de alto envolvimento e os atrativos dos outros segmentos empresariais, pode desempenhar um papel importante na redução da rotatividade no setor industrial (RONDEAU; WAGAR, 2016). Diante disso, este estudo objetiva analisar os principais fatores determinantes da rotatividade em uma empresa de grande porte do segmento metalomecânico de Caxias do Sul, Rio Grande do Sul. Para tanto, o artigo está estruturado em mais quatros seções, além da introdutória. A seguir, constam o referencial teórico sobre gestão de pessoas e rotatividade, a metodologia, a análise dos resultados e as considerações do estudo.

\section{GESTÃO DE PESSOAS}

A exigência aumentou para o setor de recursos humanos das empresas, pois o setor precisa criar e agregar valor em termos comerciais reais, devendo entender como a empresa opera (o que inclui as pressões societárias que a incentivam), bem como especificar o que molda e o que sustenta o negócio (o que abarca, clientes externos e internos, concorrentes, investidores, fornecedores, entre outros). Além disso, precisa entender a estratégia do negócio e o posicionamento da empresa diante das adversidades, a fim de criar uma vantagem competitiva sobre os concorrentes no seu mercado de atuação (ULRICH et al., 2013).

De acordo com Knapik (2008, p. 134), a motivação, elemento importante nessa conjuntura, significa "mover para a ação, mobilizar energia e esforços na busca da realização de determinadas metas". Por seu intermédio, as pessoas encontram as razões para alcançar seus objetivos de vida, sendo impulsionadas para a direção almejada. Trata-se, assim, de um processo no interior do ser humano, sendo diretamente influenciado por fatores externos (KNAPIK, 2008).

A motivação consiste em uma energia que impulsiona as pessoas na direção de algo, mas destaca que nasce dentro do indivíduo, sendo estimulada por fatores externos (Vergara, 2013). A esse respeito, cabe mencionar que, enquanto o esgotamento emocional constitui um facilitador de insatisfação no trabalho e de intenção de rotatividade, a satisfação diminui a intenção de rotatividade (LU; GURSOY, 2016).

Conforme Kyrillos e Jung (2015), nesse cenário cada vez mais competitivo, a busca pela liderança é vista como uma obsessão no mundo corporativo, fazendo com que as empresas se 
desenvolvam e apliquem diversas estratégias para chegar ao topo. Dessa forma, os gestores se esforçam para atingir as metas propostas e pressionam os seus colaboradores para obter um resultado positivo e para que os prazos sejam cumpridos. Nesse processo, a comunicação é um fator essencial no que concerne ao papel de um líder, pois é por meio dele que se transmitem as mensagens e que se pode convencer os liderados e parceiros a se envolverem em uma causa (KYRILLOS; JUNG, 2015).

Os gestores atuais devem, portanto, responder a várias questões, como de que forma construir uma relação de confiança, como explorar o potencial dos colaboradores e como construir o treinamento e o desenvolvimento das pessoas. Uma gestão moderna também deve ter a percepção das próprias emoções, a habilidade de revisar os padrões de comportamento e a capacidade de tomar decisões embasadas em fatos concretos (BARBIERI, 2016).

Em tal conjuntura, houve uma mudança nas características da rotatividade, relacionada a uma combinação entre fatores de atitude e comportamentais e, fatores externos. Para melhorar a retenção de funcionários, uma organização deve considerar fatores individuais, organizacionais e ambientais e desenvolver uma estratégia mais abrangente, incorporando todos os aspectos das configurações de trabalho e não trabalho (SAMAD; SAUFI, 2017).

\section{ROTATIVIDADE}

A relação trabalhista entre o empregador e o empregado é passível de interrupção quando uma das partes deixa de cumprir o que foi proposto no contrato de trabalho, seja por iniciativa do empregador ou do trabalhador. Esse rompimento é conhecido como rescisão do contrato de trabalho, em que o empregador caracteriza os motivos que justificam a saída do trabalhador da empresa (FIDELIS, 2014).

As empresas que enfrentam a rotatividade, lamentam a falta de sorte, abominam a concorrência ou, buscam comprar pessoas oferecendo caríssimos benefícios, quando deveriam priorizar a identificação dos padrões de rotatividade e interpretar o seu significado. A análise da rotatividade tem a finalidade de identificar trabalhadores que atendem a dois critérios: possuem capital humano que a empresa valoriza e demonstram características que os tornam possíveis candidatos a deixá-la. As organizações precisam analisar os padrões tendo em vista o quando e o porquê (DAVENPORT, 2001).

De acordo com Dornelles Filho (2013), a rotatividade de mão de obra é produzida pela movimentação de admissões e demissões nos postos de trabalho. Esse processo pode ser entendido como a composição de dois movimentos. Um deles é ponto de vista do empregador, quando o trabalhador é desligado de uma empresa e é substituído pela admissão de outro em seu lugar. O outro ponto de vista é do trabalhador, quando seu posto de trabalho em uma 
empresa é substituído por outro posto de trabalho em outra empresa.

A taxa de rotatividade pode, assim, ser definida como a razão entre o valor mínimo do número de admitidos e de desligados que representa o tamanho da interseção e os conjuntos de admitidos e desligados em dado período. A taxa de rotatividade ri no período i é descrita por Dornelles Filho (2013) pela seguinte forma.

$$
r i=\frac{\min (a i, d i)}{1 / 2(e i+e i-1)(1)}
$$

Nessa equação, ai é o número de admitidos no ano i, di é o número de desligados no ano $i$, ei é o estoque de empregos no ano $i$, ei-1 é o estoque de empregos no ano anterior. Deve-se ressaltar que essa definição não é universal, é possível utilizar no denominador da expressão o estoque no início do período (DORNELLES FILHO, 2013).

A esse respeito, destaca-se, ainda, uma ligação entre as emoções positivas e a rotatividade, motivo pelo qual esses fatores devem ser abordados de forma conjunta. Além disso, é preciso considerar que o gestor, ao adotar uma mentalidade otimista e uma comunicação eficiente no local de trabalho, exerce uma influência positiva sobre seus subordinados, devendo levar em conta a satisfação no trabalho e os sintomas de estresse para examinar os resultados no volume de negócios da organização (SIU et al., 2015).

\section{METODOLOGIA DA PESQUISA}

Este estudo se caracteriza como uma pesquisa quantitativa, que conforme Cooper e Schindler (2016), busca fazer a mensuração de uma população. Já o método empregado é descritivo, o qual, segundo Pereira (2012), visa descrever as principais características de determinada população ou estabelecer relações entre variáveis, envolvendo o uso de técnicas padronizadas de coleta de dados, tais como questionários.

A pesquisa foi realizada por meio de uma survey com a aplicação de um questionário para o levantamento e a tabulação dos dados. Para o desenvolvimento desta pesquisa, foi utilizada uma amostra não probabilística. Enquanto a população é o universo da pesquisa, a amostra é uma parcela convenientemente selecionada desse universo (LAKATOS; MARCONI, 2010).

O questionário, desenvolvido com base em Frufrek (2015), foi aplicado aos funcionários de uma empresa do segmento metalomecânico de Caxias do Sul, que representavam uma população de 100 pessoas. Após a aplicação, o número da amostra ficou em 90 respondentes, o que corresponde a 90\% da população.

Os funcionários estavam divididos por células, as quais abrangeram os setores de 
Segurança do Trabalho, Engenharia da Qualidade e Engenharia de Processos. O critério de escolha da empresa foi a disponibilidade para aplicação de uma pesquisa acadêmica, e os setores foram indicados devido aos seus altos índices de rotatividade na empresa.

A coleta dos dados ocorreu por meio de questionários, constituídos de seis questões de múltipla escolha e 15 questões com uma escala Likert de cinco pontos. Antes da aplicação com a amostra desta pesquisa, foram aplicados cinco questionários como pré-teste para os funcionários da empresa. Ressalta-se que o pré-teste, conforme Gil (2010), não pode trazer nenhum resultado referente aos objetivos, pois ele está centrado na avaliação dos instrumentos, visando, assim, garantir que estas meçam exatamente o que se pretende medir.

A técnica utilizada para a análise dos dados foi a estatística descritiva, que segundo Larson e Farber (2016), é o ramo da estatística que envolve a organização, o resumo e a representação dos dados. Além disso, a análise contou com o auxílio do software IBM $^{\circledR}$ SPSS Statistics.

\section{ANÁLISE E DISCUSSÃO DOS RESULTADOS}

Conforme Hair (2005), os dados tornam-se conhecimento somente depois de a análise ter identificado um conjunto de descrições, relações e diferenças úteis na tomada de decisão. Nesta seção, consta a análise dos resultados obtidos mediante a aplicação dos questionários que foram divididos em duas partes, a primeira avaliou o perfil socioeconômico dos entrevistados, cujos resultados são apresentados por meio de gráficos e a segunda parte averiguou os fatores da rotatividade de uma empresa do segmento metalomecânico, cujos resultados são expressos por meio de tabelas.

Na Figura 1, a seguir, pode-se perceber que 70 respondentes são do gênero masculino (78\%) e 20 são do sexo feminino (22\%).

Figura 1 - Gênero

= Feminino

- Masculino

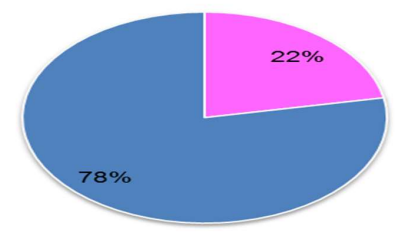

Fonte: Elaborado pelos autores (2019).

A Figura 2, referente ao estado civil dos respondentes, evidencia que 45 respondentes estão casados ou sob regime de união estável (50\%), 40 respondentes estão solteiros (44\%) e, 
05 respondentes são divorciados ou separados (6\%).

Figura 2 - Estado civil

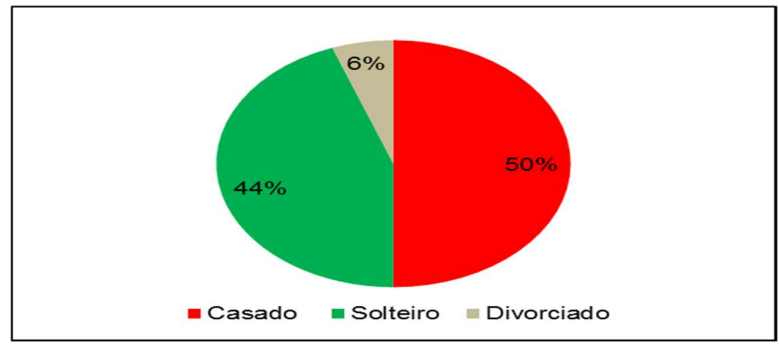

Fonte: Elaborado pelos autores (2019).

Já na Figura 3, sobre a faixa etária dos funcionários, nota-se que 45 respondentes têm de 21 a 30 anos (50\%), 32 têm entre 31 e 40 anos (36\%), 12 possuem de 41 a 50 anos (13\%) e 1 tem acima de 51 anos (1\%).

Figura 3 - Faixa etária

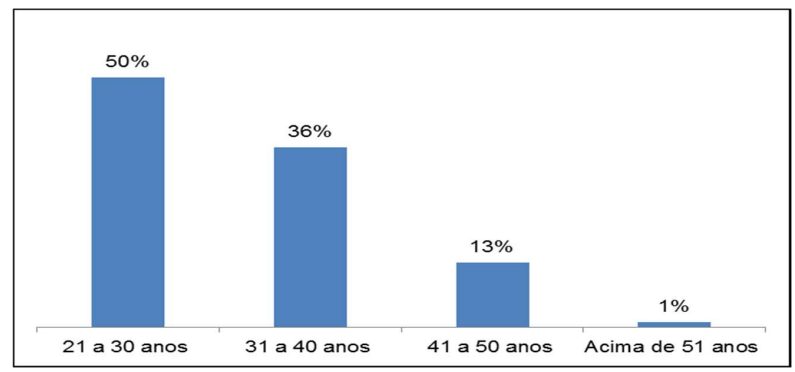

Fonte: Elaborado pelos autores (2019).

Conforme demonstra a Figura 4, quanto à renda bruta mensal, 10 respondentes ganham entre $\mathrm{R} \$ 1.001,00$ e $\mathrm{R} \$ 2.000,00$ (11\%), 10 recebem entre $\mathrm{R} \$ 2.001$ e $\mathrm{R} \$ 3.000,00$ (11\%), 19 têm renda entre $R \$ 3.001,00$ e $R \$ 4.000,00$ (21\%), 22 estão na faixa de $R \$ 4.001,00$ a $R \$ 5.000,00$ (24\%) e 29 ganham acima de $R \$ 5.001,00$ (32\%). 
Figura 4 - Renda bruta

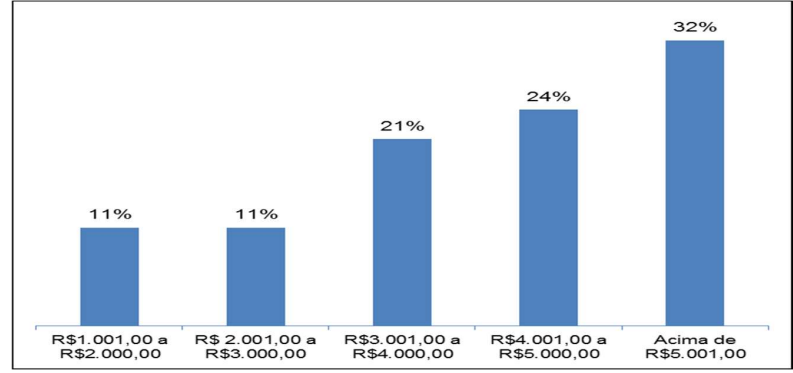

Fonte: Elaborado pelos autores (2019).

A Figura 5, por sua vez, indica o grau de instrução dos funcionários, evidenciando que 5 respondentes têm ensino médio completo (6\%), 40 participantes possuem ensino superior incompleto (44\%), 22 respondentes possuem Ensino Superior completo (24\%), 5 participantes têm Pós-Graduação incompleta (6\%) e 18 respondentes possuem Pós-Graduação completa (20\%).

Figura 5 - Grau de instrução

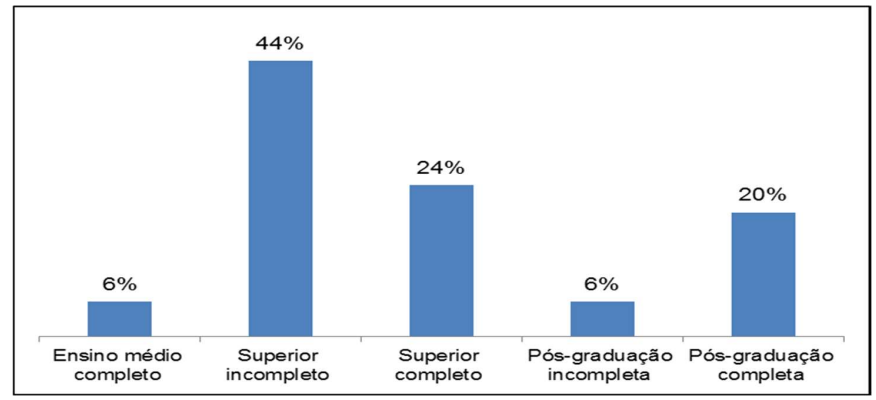

Fonte: Elaborado pelos autores (2019).

A Figura 6, que versa sobre o tempo de serviço dos funcionários, mostra que 3 respondentes possuem até seis meses de empresa (3\%), 7 têm de seis meses a um ano (8\%), 20 possuem de um à três anos (22\%), 16 têm de três à cinco anos (18\%) e 44 têm acima de cinco anos (49\%). 
Figura 6 - Tempo de serviço

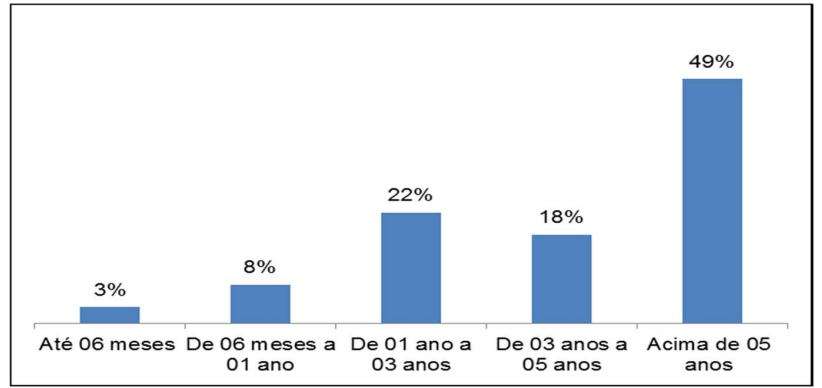

Fonte: Elaborado pelos autores (2019).

A partir da Tabela 1 até a Tabela 6, observam-se os resultados obtidos por meio do questionário sobre os fatores da rotatividade. As questões a esse respeito foram divididas, conforme a afinidade dos assuntos, nos seguintes blocos: liderança, motivação, ambiente de trabalho e plano de carreira. No Quadro 1, a seguir, consta-se o questionário sobre os fatores da rotatividade.

Quadro 1 - Fatores da rotatividade

\begin{tabular}{|c|c|}
\hline Liderança & $\begin{array}{l}05 \text { - Eu sei o que é esperado de mim no trabalho. } \\
10 \text { - Existe autonomia para resolver conflitos/melhorias na empresa. } \\
13 \text { - A liderança pode influenciar positivamente ou negativamente a equipe de } \\
\text { trabalho. }\end{array}$ \\
\hline Motivação & $\begin{array}{l}01 \text { - O atual trabalho me proporciona crescimento pessoal e profissional. } \\
06 \text { - As pessoas sentem orgulho em fazer parte da empresa. } \\
11 \text { - O trabalho atual me proporciona estabilidade e confiabilidade. } \\
15 \text { - No decorrer deste ano, tive oportunidades de aprender e progredir no trabalho. }\end{array}$ \\
\hline $\begin{array}{l}\text { Ambiente } \\
\text { de trabalho }\end{array}$ & $\begin{array}{l}02 \text { - A empresa possui um ambiente de trabalho agradável. } \\
04 \text { - Existe cooperação entre os colegas da minha equipe de trabalho. } \\
07 \text { - As instalações físicas da empresa estão em boas condições. } \\
08 \text { - No meu setor não existe conflitos entre os colegas. }\end{array}$ \\
\hline $\begin{array}{l}\text { Plano de } \\
\text { carreira }\end{array}$ & $\begin{array}{l}03 \text { - A remuneração é compatível com a função exercida. } \\
09 \text { - Existe plano de carreira na empresa onde trabalho. } \\
12 \text { - A realização de treinamentos minimiza a rotatividade de pessoal. } \\
14 \text { - A política salarial e de plano de carreira minimiza a rotatividade de pessoal. }\end{array}$ \\
\hline
\end{tabular}

Fonte: Elaborado por Frufrek (2015).

$\mathrm{Na}$ Tabela 1, referente à comparação entre os gêneros, pode-se perceber que há 70 respondentes do sexo masculino, entre os quais a liderança foi o fator mais relevante com média de 4,19, e desvio padrão de 0,63. Já a menor média foi de 3,63 atribuída ao ambiente de trabalho, sendo superior ao nível da indiferença, ou seja, superior ao grau de não concordo nem discordo e desvio padrão de 0,68.

Entre os 20 respondentes do sexo feminino, por sua vez, o fator mais relevante foi o 
plano de carreira, com média de 3,93 e desvio padrão de 0,66, e o menos relevante foi ambiente de trabalho com média de 3,54 e desvio padrão de 0,89 o qual, segundo Cooper e Schindler (2016) indica a que distância da média os valores dos dados estão normalmente. O desvio padrão também é um conceito importante para a estatística descritiva porque revela a quantidade de variabilidade dentro do conjunto de dados.

Assim, evidencia-se que $14 \%$ dos participantes do gênero masculino concordam com as afirmações do fator liderança e 13\% dos respondentes do gênero feminino não têm opinião formada sobre esse fator. Além disso, 75\% dos entrevistados distribuídos entre os dois gêneros não possuem opinião formada sobre os demais fatores. Portanto, é possível verificar que mais da metade dos gêneros não concordam nem discordam das afirmações.

A liderança exerce um papel relevante na promoção do engajamento, por consequência, o engajamento tende a reduzir a intenção de rotatividade (OLIVEIRA; COSTA ROCHA, 2017).

Tabela 1 - Comparação entre gênero

\begin{tabular}{c|c|c|c|c|c}
\hline Fatores & $\mathrm{N}^{\circ}$ de respostas & Gênero & Média & Percentual & Desvio Padrão \\
\hline \multirow{2}{*}{ Liderança } & 70 & Masculino & 4,19 & $14 \%$ & 0,63 \\
& 20 & Feminino & 3,88 & $13 \%$ & 0,85 \\
\hline \multirow{2}{*}{ Motivação } & 70 & Masculino & 3,91 & $13 \%$ & 0,70 \\
& 20 & Feminino & 3,86 & $13 \%$ & 0,69 \\
\hline \multirow{2}{*}{ Ambiente de trabalho } & 70 & Masculino & 3,63 & $12 \%$ & 0,68 \\
& 20 & Feminino & 3,54 & $11 \%$ & 0,89 \\
\hline \multirow{2}{*}{ Plano de Carreira } & 70 & Masculino & 3,88 & $13 \%$ & 0,70 \\
& 20 & Feminino & 3,93 & $13 \%$ & 0,66 \\
\hline
\end{tabular}

Fonte: Elaborado pelos autores (2019)

Na Tabela 2, concernente à comparação entre os estados civis dos entrevistados, percebe-se que há 40 respondentes solteiros, para os quais o fator mais relevante foi liderança, com média de 4,16 e desvio padrão de 0,68, e o menos relevante foi ambiente de trabalho, com média é 3,90 e um desvio padrão de 0,73. Entre os 45 casados, a média mais relevante caiu na liderança, com 4,12 e, desvio padrão de 0,71, e a menor média recaiu no ambiente de trabalho, com 3,40 e desvio padrão de 0,64. E, entre os 05 divorciados, a média mais relevante residiu no plano de carreira, com 3,85 e desvio padrão de 0,29, e a menor no ambiente de trabalho, com 3,10 e desvio padrão de 0,65.

Em relação a esse resultado, sobre o ambiente de trabalho da empresa, cabe mencionar que o primeiro passo para a solução de um problema é diagnosticar a situação atual, ou seja, identificar o problema e saber o que o causa. Nesse sentido, cita-se a pesquisa de clima organizacional, um dos instrumentos que podem ser utilizados para o levantamento do clima, com o objetivo de verificar o grau de satisfação dos empregados em relação à empresa (FERREIRA, 2013). 
Deve-se observar, ainda, os resultados entre solteiros (36\%) $27 \%$ concordam com as afirmações de liderança, motivação e plano de carreira, e 9\% não concordam nem discordam. Entre os casados (32\%), 9\% concordam com o fator liderança e $23 \%$ não concordam nem discordam dos demais fatores. E, entre os divorciados (31\%), não há opinião formada sobre esses fatores.

Tabela 2 - Comparação entre estado civil

\begin{tabular}{c|c|c|c|c|c}
\hline Fatores & $\mathrm{N}^{\circ}$ de respostas & Estado civil & Média & Percentual & Desvio Padrão \\
\hline Liderança & \multirow{3}{*}{40} & & 4,16 & $9 \%$ & 0,68 \\
Motivação & \multirow{2}{*}{ Solteiro } & 4,06 & $9 \%$ & 0,71 \\
Ambiente de Trabalho & & & 3,90 & $9 \%$ & 0,73 \\
Plano de Carreira & & & 4,06 & $9 \%$ & 0,71 \\
\hline Liderança & \multirow{3}{*}{45} & \multirow{3}{*}{ Casado } & 3,12 & $9 \%$ & 0,71 \\
Motivação & & & 3,40 & $8 \%$ & 0,68 \\
Ambiente de Trabalho & & & 3,74 & $8 \%$ & 0,64 \\
Plano de Carreira & & & 3,80 & $8 \%$ & 0,67 \\
\hline Liderança & \multirow{3}{*}{5} & Divorciado & 3,75 & $8 \%$ & 0,61 \\
Motivação & & & 3,10 & $7 \%$ & 0,40 \\
Ambiente de Trabalho & & & 3,85 & $8 \%$ & 0,65 \\
Plano de Carreira & & & & \\
\hline
\end{tabular}

Fonte: Elaborado pelos autores (2019).

$\mathrm{Na}$ Tabela 3, que representa a comparação entre faixa etária, observa-se há 45 respondentes na faixa de 21 a 30 anos, para os quais a média mais relevante foi a liderança com 4,25 e desvio padrão de 0,48, e a menor média foi o ambiente de trabalho, com 3,86 e desvio padrão de 0,69. Nota-se, ainda, que existem 32 participantes na faixa de 31 a 40 anos, entre os quais a média mais relevante foi a liderança, com 3,88 e desvio padrão de 0,90 , e a menor média foi o ambiente de trabalho, com 3,23 e desvio padrão de 0,68.

Entre os 12 respondentes na faixa de 41 a 50 anos, a média mais relevante foi 3,94 (ambiente de trabalho), com desvio padrão de 0,64, e a menor média foi 3,19 (motivação), com desvio padrão de 0,71. Para o único respondente acima de 51 anos, a média mais relevante foi o plano de carreira, com 5,00, e a menor foi o ambiente de trabalho com 4,00, não havendo desvio padrão neste caso. Pode-se considerar que as médias, tanto as mais relevantes quanto as menos relevantes, foram superiores ao nível da indiferença, ou seja, superior ao grau de "não concordo nem discordo", tendo uma tendência à opção "de acordo".

O papel do setor de recursos humanos é importante no apoio ao desenvolvimento da liderança desses gerentes de linha de frente, de modo que a adoção da liderança transformacional pode ajudar a facilitar o trabalho realizado e promover o bem-estar do funcionário melhorando as taxas de retenção (CHENG, 2016). Isso vai ao encontro do fato de que, na faixa etária de 21 a 30 anos (25\%), 19\% concordam com os fatores de liderança, motivação e plano de carreira e 6\% não concordam nem discordam, e 31 a 40 anos, (23\%) nem concordam nem discordam, de 41 a 50 anos (24\%) não possuem opinião formada sobre esses fatores, e, acima de 51 anos, (28\%) os resultados foram de concordo à concordo totalmente. 
Tabela 3 - Comparação entre faixa etária

\begin{tabular}{|c|c|c|c|c|c|}
\hline Fatores & $\mathrm{N}^{\circ}$ de respostas & Faixa etária & Média & Percentual & Desvio Padrão \\
\hline $\begin{array}{c}\text { Liderança } \\
\text { Motivação } \\
\text { Ambiente de Trabalho } \\
\text { Plano de Carreira }\end{array}$ & 45 & 21 à 30 & $\begin{array}{l}4,25 \\
4,09 \\
3,86 \\
4,05\end{array}$ & $\begin{array}{l}7 \% \\
6 \% \\
6 \% \\
6 \%\end{array}$ & $\begin{array}{l}0,48 \\
0,54 \\
0,69 \\
0,68\end{array}$ \\
\hline $\begin{array}{c}\text { Liderança } \\
\text { Motivação } \\
\text { Ambiente de Trabalho } \\
\text { Plano de Carreira }\end{array}$ & 32 & 31 à 40 & $\begin{array}{l}3,88 \\
3,58 \\
3,23 \\
3,62\end{array}$ & $\begin{array}{l}6 \% \\
5 \% \\
6 \% \\
6 \%\end{array}$ & $\begin{array}{l}0,90 \\
0,78 \\
0,68 \\
0,64\end{array}$ \\
\hline $\begin{array}{c}\text { Liderança } \\
\text { Motivação } \\
\text { Ambiente de Trabalho } \\
\text { Plano de Carreira }\end{array}$ & 12 & 41 à 50 & $\begin{array}{l}3,80 \\
3,19 \\
3,94 \\
3,87\end{array}$ & $\begin{array}{l}5 \% \\
6 \% \\
6 \% \\
7 \% \\
\end{array}$ & $\begin{array}{l}0,61 \\
0,71 \\
0,64 \\
0,62\end{array}$ \\
\hline $\begin{array}{c}\text { Liderança } \\
\text { Motivação } \\
\text { Ambiente de Trabalho } \\
\text { Plano de Carreira }\end{array}$ & 1 & Acima de 51 & $\begin{array}{l}4,67 \\
4,75 \\
4,00 \\
5,00\end{array}$ & $\begin{array}{l}7 \% \\
7 \% \\
6 \% \\
8 \%\end{array}$ & - \\
\hline
\end{tabular}

Fonte: Elaborado pelos autores (2019).

$\mathrm{Na}$ Tabela 4, que se destina a realizar uma comparação entre renda, percebe-se que há 10 respondentes que ganham entre $\mathrm{R} \$ 1.001,00$ a $\mathrm{R} \$ 2.000,00$, para os quais os fatores relevantes foram motivação e ambiente de trabalho, ambos com média de 4,37 e desvio padrão de 0,46 e 0,81, respectivamente. O fator menos relevante foi plano de carreira com média de 4,15 e desvio padrão de 0,69. Entre os 10 respondentes que recebem de $\mathrm{R} \$ 2.001,00$ a $\mathrm{R} \$ 3.000,00$, o fator mais relevante foi liderança, com média de 4,23 e desvio padrão de 0,39, e o menos relevante foi ambiente de trabalho, com média de 3,62 e desvio padrão de 0,50.

Para os 19 respondentes que se enquadram na faixa salarial de $\mathrm{R} \$ 3.001,00$ a $\mathrm{R} \$$ $4.000,00$, a média mais relevante $(4,09)$ foi liderança, com desvio padrão de 0,51 , e a menor média foi ambiente de trabalho $(3,58)$, com desvio padrão de 0,66 . Para os 22 respondentes que ganham de $R \$ 4.001,00$ a $R \$ 5.000,00$, a média mais relevante foi de 3,88 , no fator liderança, com desvio padrão de 0,87 , e a menos relevante foi de 3,22 , no fator ambiente de trabalho, com desvio padrão de 0,87 . Já para os que recebem acima de $\mathrm{R} \$ 5.001,00$, o fator mais relevante foi liderança com média de 4,24 e desvio padrão de 0,78 e o menos relevante foi ambiente de trabalho, com média de 3,63 e desvio padrão de 0,59.

Para Knapik (2008), a motivação é importante para alcançar vantagem competitiva, visto que um funcionário motivado gera qualidade nos serviços prestados. Ao encontro disso, os resultados deste estudo indicam que, entre os respondentes que possuem renda de $\mathrm{R} \$$ $1.001,00$ a $\mathrm{R} \$ 2.000,00,22 \%$ concordam com as afirmações dos fatores. Entre os que ganham de $R \$ 2.001,00$ à $R \$ 3.000,00,14 \%$ concordam e $5 \%$ não concordam nem discordam. Entre os que recebem de $\mathrm{R} \$ 3.001,00$ à $\mathrm{R} \$ 4.000,00,15 \%$ não têm opinião formada, e 5\% concordam. Entre os que recebem de $\mathrm{R} \$ 4.001,00$ a $\mathrm{R} \$ 5.000,00,18 \%$ não concordam nem discordam, e, entre os que ganham acima de $\mathrm{R} \$ 5.001,00$ 10\% que concordam e $10 \%$ não concordam e nem discordam das afirmações.

Tendo isso em vista, ressalta-se que o comprometimento afetivo está relacionado a 
intenção de rotatividade (WONG et al., 2015) e que a rotatividade dos funcionários é um problema sério com o qual todas as organizações precisam lidar. Além disso, destaca-se que a falta de integração no ambiente e problemas de relacionamento são as maiores causas dessa problemática (GUPTA, 2018).

Tabela 4 - Comparação entre renda

\begin{tabular}{|c|c|c|c|c|c|}
\hline Fatores & $\mathrm{N}^{\circ}$ de respostas & Renda & Média & Percentual & Desvio Padrão \\
\hline $\begin{array}{c}\text { Liderança } \\
\text { Motivação } \\
\text { Ambiente de Trabalho } \\
\text { Plano de Carreira }\end{array}$ & 10 & 1001 à 2000 & $\begin{array}{l}4,20 \\
4,37 \\
4,37 \\
4,15\end{array}$ & $\begin{array}{l}5 \% \\
6 \% \\
6 \% \\
5 \%\end{array}$ & $\begin{array}{l}0,48 \\
0,46 \\
0,81 \\
0,69\end{array}$ \\
\hline $\begin{array}{c}\text { Liderança } \\
\text { Motivação } \\
\text { Ambiente de Trabalho } \\
\text { Plano de Carreira } \\
\end{array}$ & 10 & 2001 à 3000 & $\begin{array}{l}4,23 \\
4,00 \\
3,62 \\
4,12 \\
\end{array}$ & $\begin{array}{l}5 \% \\
5 \% \\
5 \% \\
5 \% \\
\end{array}$ & $\begin{array}{l}0,39 \\
0,39 \\
0,50 \\
0,32 \\
\end{array}$ \\
\hline $\begin{array}{c}\text { Liderança } \\
\text { Motivação } \\
\text { Ambiente de Trabalho } \\
\text { Plano de Carreira }\end{array}$ & 19 & 3001 à 4000 & $\begin{array}{l}4,09 \\
3,96 \\
3,58 \\
3,76\end{array}$ & $\begin{array}{l}5 \% \\
5 \% \\
5 \% \\
5 \%\end{array}$ & $\begin{array}{l}51 \% \\
44 \% \\
66 \% \\
71 \%\end{array}$ \\
\hline $\begin{array}{c}\text { Liderança } \\
\text { Motivação } \\
\text { Ambiente de Trabalho } \\
\text { Plano de Carreira }\end{array}$ & 22 & 4001 à 5000 & $\begin{array}{l}3,88 \\
3,36 \\
3,22 \\
3,59\end{array}$ & $\begin{array}{l}5 \% \\
4 \% \\
4 \% \\
5 \%\end{array}$ & $\begin{array}{l}0,87 \\
0,86 \\
0,77 \\
0,76\end{array}$ \\
\hline $\begin{array}{c}\text { Liderança } \\
\text { Motivação } \\
\text { Ambiente de Trabalho } \\
\text { Plano de Carreira }\end{array}$ & 28 & $\begin{array}{c}\text { Acima de } \\
5001\end{array}$ & $\begin{array}{l}4,24 \\
4,03 \\
3,63 \\
3,98\end{array}$ & $\begin{array}{l}5 \% \\
5 \% \\
5 \% \\
5 \%\end{array}$ & $\begin{array}{l}0,78 \\
0,63 \\
0,59 \\
0,63\end{array}$ \\
\hline
\end{tabular}

Fonte: Elaborado pelos autores (2019).

A insatisfação no ofício, a falta de comprometimento na organização, o desempenho profissional, a procura de emprego e as oportunidades de trabalho estão entre as principais causas de rotatividade de funcionários. Dessa maneira, a evolução da retenção começa no foco da empresa em uma combinação de fatores econômicos e fatores ambientais (SAMAD; SAUFI, 2017).

$\mathrm{Na}$ Tabela 5, que fornece um cotejo entre grau de instrução, percebe-se que há 5 respondentes com ensino médio completo, para os quais o fator mais relevante foi a liderança, com 4,13 e desvio padrão de 0,87 , e a menos importante foi o ambiente de trabalho, com média de 4,50 e desvio padrão de 0,73. Entre os 40 entrevistados com ensino superior incompleto, o fator em destaque foi a liderança, com média 4,13 e desvio padrão de 0,52, e com menor média $(3,74)$ foi o ambiente de trabalho, que apresentou um desvio padrão de 0,75 .

Já entre os 22 respondentes com o ensino superior completo, a média mais significativa foi de 3,97 para a liderança, com desvio padrão de 0,80 e a menor foi de 3,34 para o ambiente de trabalho, com desvio padrão de 0,76. Para os 5 participantes com PósGraduação incompleta, a média mais relevante foi de 4,25 para o plano de carreira, com desvio padrão de 0,47 e a menor média foi de 3,85 para o ambiente de trabalho, com desvio padrão de 0,60 . No caso dos respondentes com Pós-Graduação completa, a média mais relevante foi liderança, com 4,24 e desvio padrão de 0,94, e a menor foi ambiente de trabalho com 3,57 e 
desvio padrão de 0,65.

Ao encontro dos resultados obtidos nesta pesquisa acerca da liderança, Madruga (2014) afirma que liderar é um caminho viável e gratificante, que proporciona significados e benefícios para a vida pessoal e profissional dos envolvidos. Quando se alcança a liderança, são beneficiados os colaboradores, os clientes, os acionistas e o próprio indivíduo que se tornou líder.

Tanto as práticas de recursos humanos quanto a qualidade da relação líder-liderado podem influenciar o engajamento dos empregados, evidenciando a importância de investimentos nessas áreas por parte das empresas. O engajamento também está associado a diferenças individuais e, portanto, a construção de uma força de trabalho engajada pode exigir estratégias de seleção que privilegiem trabalhadores mais positivos a respeito de si mesmos (OLIVEIRA; COSTA ROCHA, 2017).

Dessa forma, verifica-se que, quanto ao grau de instrução, entre os que possuem ensino médio completo (21\%), 15\% não concordam e nem discordam, e 6\% concordam com as afirmações sobre os fatores que afetam a rotatividade. Entre os que possuem, ensino superior incompleto (21\%), 15\% não concordam nem discordam e, $6 \%$ concordam, e entre os que têm superior completo (20\%), não concordam nem discordam. Já entre os que possuem PósGraduação incompleta, 17\% concordam, e 5\% não concordam nem discordam. E, entre os que apresentam Pós-Graduação completa (21\%), 15\% não concordam nem discordam e 6\% concordam com as afirmações a respeito dos fatores.

Tabela 5 - Comparação entre grau de instrução

\begin{tabular}{|c|c|c|c|c|c|}
\hline Fatores & $N^{\circ}$ de respostas & $\begin{array}{c}\text { Grau de } \\
\text { instrução }\end{array}$ & Média & Percentual & Desvio Padrão \\
\hline $\begin{array}{c}\text { Liderança } \\
\text { Motivação } \\
\text { Ambiente de Trabalho } \\
\text { Plano de Carreira }\end{array}$ & 5 & $\begin{array}{l}\text { Ensino médio } \\
\text { completo }\end{array}$ & $\begin{array}{l}4,13 \\
3,70 \\
3,50 \\
3,75\end{array}$ & $\begin{array}{l}6 \% \\
5 \% \\
5 \% \\
5 \%\end{array}$ & $\begin{array}{l}0,87 \\
0,82 \\
0,73 \\
0,68\end{array}$ \\
\hline $\begin{array}{c}\text { Liderança } \\
\text { Motivação } \\
\text { Ambiente de Trabalho } \\
\text { Plano de Carreira }\end{array}$ & 40 & $\begin{array}{l}\text { Superior } \\
\text { incompleto }\end{array}$ & $\begin{array}{l}4,13 \\
3,99 \\
3,74 \\
3,88\end{array}$ & $\begin{array}{l}6 \% \\
5 \% \\
5 \% \\
5 \%\end{array}$ & $\begin{array}{l}0,52 \\
0,54 \\
0,75 \\
0,76\end{array}$ \\
\hline $\begin{array}{c}\text { Liderança } \\
\text { Motivação } \\
\text { Ambiente de Trabalho } \\
\text { Plano de Carreira }\end{array}$ & 22 & $\begin{array}{l}\text { Superior } \\
\text { completo }\end{array}$ & $\begin{array}{l}3,97 \\
3,64 \\
3,34 \\
3,74\end{array}$ & $\begin{array}{l}5 \% \\
5 \% \\
5 \% \\
5 \%\end{array}$ & $\begin{array}{l}0,80 \\
0,85 \\
0,76 \\
0,60\end{array}$ \\
\hline $\begin{array}{c}\text { Liderança } \\
\text { Motivação } \\
\text { Ambiente de Trabalho } \\
\text { Plano de Carreira }\end{array}$ & 5 & $\begin{array}{c}\text { Pós - } \\
\text { graduação } \\
\text { incompleta }\end{array}$ & $\begin{array}{l}4,20 \\
4,05 \\
3,85 \\
4,25 \\
\end{array}$ & $\begin{array}{l}6 \% \\
5 \% \\
5 \% \\
6 \% \\
\end{array}$ & $\begin{array}{l}0,30 \\
0,57 \\
0,60 \\
0,47 \\
\end{array}$ \\
\hline $\begin{array}{c}\text { Liderança } \\
\text { Motivação } \\
\text { Ambiente de Trabalho } \\
\text { Plano de Carreira }\end{array}$ & 17 & $\begin{array}{c}\text { Pós - } \\
\text { graduação } \\
\text { completa }\end{array}$ & $\begin{array}{l}4,24 \\
3,97 \\
3,57 \\
3.97\end{array}$ & $\begin{array}{l}6 \% \\
5 \% \\
5 \% \\
5 \%\end{array}$ & $\begin{array}{l}0,94 \\
0,75 \\
0,65 \\
0,65\end{array}$ \\
\hline
\end{tabular}

Fonte: Elaborado pelos autores (2019).

Conforme evidenciada a Tabela 6, referente ao tempo de serviço, há 3 respondentes com até seis meses de empresa, entre os quais a média mais relevante foi ambiente de trabalho, com 4,83 e desvio padrão de 0,14, e a menos relevante foi plano de carreira, com 4,58 e desvio padrão de 0,52. Entre os 7 participantes com seis meses a um de trabalho na 
empresa, a média mais relevante foi a motivação, com 4,29 e desvio padrão de 0,22 e a menos relevante foi o ambiente de trabalho, com 4,07 e desvio padrão de 0,81 .

Já entre os 20 respondentes com um ano a três anos de trabalho na empresa, o fator mais significativo foi a liderança, com média de 3,98 e desvio padrão de 0,48, e menos significativo foi ambiente de trabalho, com média de 3,58 ambiente de trabalho e desvio padrão de 0,62. Para os 16 respondentes com três anos a cinco anos de atuação na empresa, liderança foi o fator em destaque com média de 3,85 e desvio padrão de 0,62, e com menor média $(3,08)$ foi ambiente de trabalho, que apresentou desvio padrão de 0,69. Entre aqueles com mais de cinco anos na empresa, a média mais relevante foi liderança $(4,22)$ e desvio padrão de 0,82 , e a menos importante foi ambiente de trabalho $(3,65)$, com desvio padrão de 0,65 .

Tabela 6 - Comparação tempo de empresa

\begin{tabular}{|c|c|c|c|c|c|}
\hline Fatores & $N^{\circ}$ de respostas & $\begin{array}{l}\text { Tempo de } \\
\text { serviço }\end{array}$ & Média & Percentual & Desvio Padrão \\
\hline $\begin{array}{c}\text { Liderança } \\
\text { Motivação } \\
\text { Ambiente de Trabalho } \\
\text { Plano de Carreira }\end{array}$ & 3 & Até 06 meses & $\begin{array}{l}4,78 \\
4,67 \\
4,83 \\
4,58\end{array}$ & $\begin{array}{l}6 \% \\
6 \% \\
6 \% \\
6 \%\end{array}$ & $\begin{array}{l}0,19 \\
0,58 \\
0,14 \\
0,52\end{array}$ \\
\hline $\begin{array}{c}\text { Liderança } \\
\text { Motivação } \\
\text { Ambiente de Trabalho } \\
\text { Plano de Carreira }\end{array}$ & 7 & $\begin{array}{c}06 \text { meses a } 01 \\
\text { ano }\end{array}$ & $\begin{array}{l}4,14 \\
4,29 \\
4,07 \\
4,21\end{array}$ & $\begin{array}{l}5 \% \\
5 \% \\
5 \% \\
5 \%\end{array}$ & $\begin{array}{l}0,33 \\
0,22 \\
0,81 \\
0,47\end{array}$ \\
\hline $\begin{array}{c}\text { Liderança } \\
\text { Motivação } \\
\text { Ambiente de Trabalho } \\
\text { Plano de Carreira }\end{array}$ & 20 & $\begin{array}{c}01 \text { ano a } 03 \\
\text { anos }\end{array}$ & $\begin{array}{l}3,98 \\
3,89 \\
3,58 \\
3,85\end{array}$ & $\begin{array}{l}5 \% \\
5 \% \\
4 \% \\
5 \%\end{array}$ & $\begin{array}{l}0,48 \\
0,38 \\
0,62 \\
0,42\end{array}$ \\
\hline $\begin{array}{c}\text { Liderança } \\
\text { Motivação } \\
\text { Ambiente de Trabalho } \\
\text { Plano de Carreira }\end{array}$ & 16 & $\begin{array}{c}03 \text { anos a } 05 \\
\text { anos }\end{array}$ & $\begin{array}{l}3,85 \\
3,41 \\
3,08 \\
3,77\end{array}$ & $\begin{array}{l}5 \% \\
4 \% \\
4 \% \\
5 \%\end{array}$ & $\begin{array}{l}0,62 \\
0,69 \\
0,69 \\
0,51\end{array}$ \\
\hline $\begin{array}{c}\text { Liderança } \\
\text { Motivação } \\
\text { Ambiente de Trabalho } \\
\text { Plano de Carreira }\end{array}$ & 43 & $\begin{array}{c}\text { Acima de } 05 \\
\text { anos }\end{array}$ & $\begin{array}{l}4,22 \\
3,95 \\
3,65 \\
3,82\end{array}$ & $\begin{array}{l}5 \% \\
5 \% \\
5 \% \\
5 \%\end{array}$ & $\begin{array}{l}0,82 \\
0,76 \\
0,65 \\
0,83\end{array}$ \\
\hline
\end{tabular}

Fonte: Elaborado pelos autores (2019).

Os funcionários têm uma compreensão mais clara de seus objetivos quando seus líderes praticam a liderança transformacional. Diante disso, acredita-se que os líderes transformacionais sejam capazes de alcançar tais resultados porque tendem a articular metas claras instruindo os funcionários sobre como desempenhar suas funções e possibilitando-lhes desenvolvimento profissional (CAILLIER, 2016).

Pode-se considerar na Tabela 6 que as médias, tanto as maiores quanto as menores, foram superiores ao nível da indiferença, ou seja, superiores ao grau de "não concordo nem discordo", tendo uma tendência à opção "de acordo". No caso da questão sobre os fatores de rotatividade, tendo em vista o tempo de empresa, observa-se que até seis meses de empresa (24\%), os entrevistados concordam com as afirmações, e de seis meses a um ano (20\%), concordam. De um ano a três anos (19\%), nem concordam nem discordam. De três a cinco anos (18\%), não concordam nem discordam, e acima de cinco anos (20\%), 15\% não discordam 
nem concordam, e 5\% concordam com as afirmações.

Ressalta-se, assim, que, com a implementação de estratégias bem-sucedidas para reduzir a rotatividade de funcionários, as operações e a lucratividade dos negócios podem ser poupadas no que concerne à degradação das interrupções operacionais, devido ao recrutamento frequente e à falta de mão de obra (SMITH, 2018). Além disso, a dedicação e o bom ambiente de trabalho são os indicativos que levam, de modo significativo à satisfação no trabalho e à redução das intenções de rotatividade. Embora a satisfação no trabalho possa ser aumentada pela melhoria do envolvimento dos funcionários em suas funções, apenas essa estratégia pode não ser uma solução eficaz para melhorar a satisfação no trabalho (LU et al., 2016).

\section{CONSIDERAÇÕES FINAIS}

Esta pesquisa teve como objetivo analisar os principais fatores que influenciam a rotatividade de uma empresa do segmento metalomecânico de Caxias do Sul, abrangendo os setores de Segurança do Trabalho, Engenharia da Qualidade e Engenharia de Processos. O estudo aponta que o fator ambiente de trabalho é o principal responsável pela rotatividade na empresa. Diante dessa conjuntura, os profissionais da área de recursos humanos dessa empresa devem estar atentos aos primeiros sinais de turnover, estimar as possíveis consequências, que podem ser positivas ou negativas, fazer implantações de políticas e práticas para um controle eficaz do problema e antecipar futuras causas para o gerenciamento da rotatividade.

A partir dos conceitos teóricos evidenciados nesta investigação sobre o tema da rotatividade, foi possível aprender sobre os principais fatores que influenciam na rotatividade. Tal apropriação teórica contribuiu para que o objetivo proposto fosse atingido e permitiu depreender que o assunto da rotatividade causa impactos relevantes na estrutura de uma empresa.

Pode-se concluir que cada fator tem seu grau de importância dentro da empresa estudada, sendo a liderança ponto mais forte e o ambiente de trabalho ponto mais fraco. Contudo, a motivação está diretamente ligada à rotatividade, pois um funcionário motivado rende mais para a empresa, trabalha de forma mais feliz e apresenta um grau de satisfação maior. Desse modo, uma empresa sem plano de carreira, por exemplo, também impacta na motivação de seus colaboradores, visto que as pessoas buscam reconhecimento e crescimento profissional ao longo de sua jornada de trabalho.

Além disso, ressalta-se que a boa liderança contribui para a equipe como um todo, pois um líder exerce forte influência sobre os funcionários e contribui para a formação de profissionais mais competentes e alinhados com os objetivos da empresa. O ambiente de 
trabalho, por sua vez, constitui um fator muito relevante para os funcionários, pois determina as condições em que estes passam a maior parte do seu dia, motivo pelo qual é importante que haja um clima agradável de coleguismo e cooperação entre todos. Quando isso não ocorre, a chance de haver rotatividade é grande.

Conclui-se, ainda, que uma empresa saudável com pontos positivos atrai seus funcionários, e lhe despertam o desejo de continuar trabalhando na mesma empresa por um período longo de tempo, e minimizando assim, a rotatividade de pessoal que preocupa tantos empregadores nesse segmento. Com o índice de rotatividade reduzido, a empresa terá maior segurança em relação à estabilidade dos seus funcionários, pois estes se dedicarão mais ao trabalho, garantindo desempenho e eficiência, uma vez que, com novas políticas de recursos humanos implantadas, o ambiente de trabalho estará propício para que tanto os objetivos individuais dos funcionários, quanto os objetivos da empresa sejam alcançados. Ademais, a empresa diminui custos decorrentes da rotatividade, a exemplo de custos de contratação e rescisão, bem como de treinamentos e integração de funcionários iniciantes.

Quanto as limitações desta pesquisa, destaca-se que a amostra utilizada não permite generalizações e que houve, certo desconforto por parte dos respondentes ao preencherem os questionários, em virtude de uma das autoras ser colaboradora da empresa estudada, o que pode ter ocasionado influência nas respostas dos entrevistados. Em relação a pesquisas futuras, sugere-se realizar um estudo com o mesmo escopo teórico, mas em outros setores econômicos, como comércio e serviços. Também se sugere efetuar uma pesquisa no mesmo setor, mas com abordagem qualitativa.

\section{REFERÊNCIAS}

BARBIERI, U. F. Gestão de pessoas nas organizações: conceitos básicos e aplicações. São Paulo: Atlas, 2016.

CAILLIER, J. G. Linking transformational leadership to self-efficacy, extra-role behaviors, and turnover intentions in public agencies: The mediating role of goal clarity. Administration \& Society, v. 48, n. 7, p. 883-906, 2016.

CHENG, C. et al. Transformational leadership and social identity as predictors of team climate, perceived quality of care, burnout and turnover intention among nurses. Personnel Review, $\mathrm{v}$. 45, n. 6, p. 1200-1216, 2016.

COOPER, D. R., SCHINDLER, Pamela S. Métodos de pesquisa em administração. 12. ed. AMGH, 2016.

CORRÊA, H. L., CAON, M. Gestão de serviços: lucratividade por meio de operações e de satisfação dos clientes. São Paulo: Atlas, 2012. 
DORNELLES FILHO, A. A. Relação entre o crescimento do produto e o desenvolvimento do trabalhador no setor de serviços em Caxias do Sul. Caxias do Sul: EDUCS, 2013.

FERREIRA, P. I. Gestão de Pessoas: Clima Organizacional e Qualidade de Vida no Trabalho. São Paulo: LTC, 2013.

FIDELIS, G. J. Gestão de pessoas: rotinas trabalhistas e dinâmicas do departamento de pessoal. 3. ed. Vital Source Bookshelf Online, 2014.

FRUFREK, Guilherme Luiz. Um estudo sobre a rotatividade de pessoal entre profissionais de empresas brasileiras de desenvolvimento de software. 2015. Dissertação de Mestrado. Universidade Tecnológica Federal do Paraná. 2015.

GIL, A. C. Como elaborar projetos de pesquisa. 5. ed. São Paulo: Atlas, 2010.

GUPTA, P. D. et al. Relationship between onboarding experience and turnover intention: intervening role of locus of control and self-efficacy. Industrial and Commercial Training, v. 50, n. 2, p. 61-80, 2018.

KNAPIK, J. Gestão de pessoas e talentos. 3. ed. Curitiba: IBPEX, 2008.

KYRILLOS, L.; JUNG, M. Comunicar para liderar. 1. ed. São Paulo: Contexto, 2015.

LAKATOS, E. M.; MARCONI, Marina de Andrade. Fundamentos de metodologia científica. 7. ed. São Paulo: Atlas, 2010.

LARSON, R; FARBER, B. Estatística Aplicada. 6 ed. São Paulo: Pearson Prentice Hall, 2016.

LIMONGI, A. F. Práticas de recursos humanos - PRH: conceitos, ferramentas e procedimentos. São Paulo: Atlas, 2012.

LU, A. C. C; GURSOY, D. Impact of job burnout on satisfaction and turnover intention: Do generational differences matter?. Journal of Hospitality \& Tourism Research, v. 40, n. 2, p. 210-235, 2016.

LU, Lu et al. Work engagement, job satisfaction, and turnover intentions: A comparison between supervisors and line-level employees. International Journal of Contemporary Hospitality Management, v. 28, n. 4, p. 737-761, 2016.

MADRUGA, R. Triunfo da liderança: práticas, estratégias e técnicas diárias para desenvolver líderes de alta performance. 2. ed. Atlas, 06/2014. Vital Source Bookshelf Online.

OBSERVATÓRIO DO TRABALHO, Boletim trimestral mercado formal de trabalho de Caxias do Sul [recurso eletrônico] / UCS, NID. - (out./dez. 2010) - Dados eletrônicos. - Caxias do Sul, RS: UCS, 2011.

OLIVEIRA, L. B. de; COSTA ROCHA, J. da. Engajamento no trabalho: antecedentes individuais e situacionais e sua relação com a intenção de rotatividade. Revista Brasileira de Gestão de 
Negócios, v. 19, n. 65, p. 415-431, 2017.

PEREIRA, J. Manual de metodologia da pesquisa científica. 3. ed. São Paulo: Atlas, 2012.

RONDEAU, K. V.; WAGAR, T. H. Human resource management practices and nursing turnover. Journal of Nursing Education and Practice, v. 6, n. 10, p. 101, 2016.

SAMAD, A.; SAUFI, R. A. A Comparative Review of Turnover Models and Recent Trends in Turnover Literature, 2017.

SIU, O. L.; CHEUNG, F.; LUI, S. Linking positive emotions to work well-being and turnover intention among Hong Kong police officers: The role of psychological capital. Journal of happiness studies, v. 16, n. 2, p. 367-380, 2015.

SMITH, J. D. Estratégias de sucesso para reduzir a rotatividade de funcionários na indústria de restaurantes. 2018. Tese de Doutorado. Universidade Walden.

ULRICH, D., et al. RH de Dentro para Fora: Seis competências para o futuro da área de recursos humanos. Porto Alegre: Bookman, 2013.

VERGARA, S. C. Gestão de pessoas. 14. ed. São Paulo: Atlas, 2013.

WONG, Y.; WONG, Y. W.; WONG, C. An integrative model of turnover intention: Antecedents and their effects on employee performance in Chinese joint ventures. Journal of Chinese Human Resource Management, v. 6, n. 1, p. 71-90, 2015. 